\title{
Manufacturing of Micro Electrode through Wire Electric Discharge Grinding [WEDG] and Optimize the Machining Parameters
}

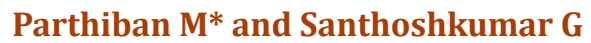 \\ Department of Mechanical Engineering, India \\ *Corresponding author: Parthiban M, Department of Mechanical Engineering, Coimbatore, India,
}

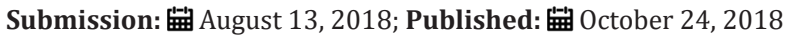

\section{Wire Electric Discharge Grinding [WEDG]}

Machining miniature cylindrical parts are of great challenge because the pressure that tools or grinding wheels exert on parts such as the micro parts/electrodes can cause the parts to deflect, making it difficult to achieve the desired accuracy. In fact, in some cases it's impossible to machine such tiny parts using these conventional methods. Unlike traditional cutting and grinding processes, which rely on the force generated by a harder tool or abrasive materials to remove the softer work piece material, the electrical discharge machining [EDM] process utilizes electrical sparks or thermal energy to erode the unwanted material and generate the desired shape. One further improvement is to rotate parts in a spindle mounted on the table of a wire EDM unit and allow the wire to "grind" the parts to shape and size. This is advantageous for micro-machining applications where material is removed electrically via spark erosion, not mechanically. The chance for deflection is eliminated because work piece and wire never touch in addition, the wire EDM unit can be easily programmed to machine contoured round features, whereas grinding operations would require longer setup times and contoured wheels. WEDG employs a set of wire guides to confine the wire tension within the discharge area between the rod and the front edge of the wire and to minimize the wire vibration. One of the advantages of WEDG is its ability to machine choice of complex shapes such as tapered and stepped shapes at various sections.

At present an experimental setup of a submergible rotary axis for the WEDM is built as show in Figure $1 \& 2$ to machine micro parts. With the help of the available experimental setup at PSG, experiments were done by machining a $\phi 2.0 \mathrm{~mm}$ HSS rod to $\phi 0.4 \mathrm{~mm}$ rod to analyze the process parameters of WEDG. The photograph of a specimen is given in Figure 3.

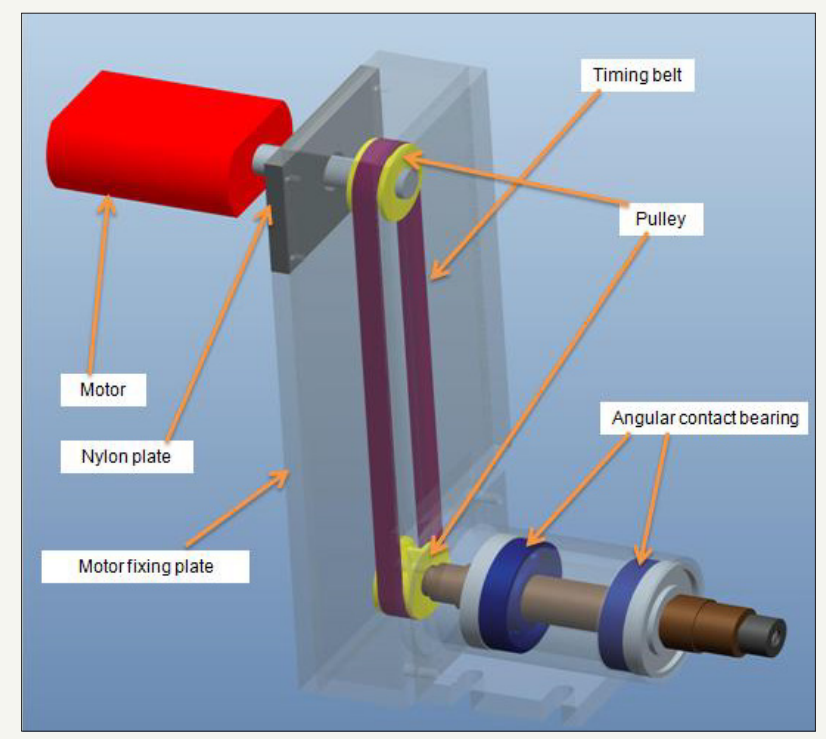

Figure 1: Schematic diagram of the experimental set up. 


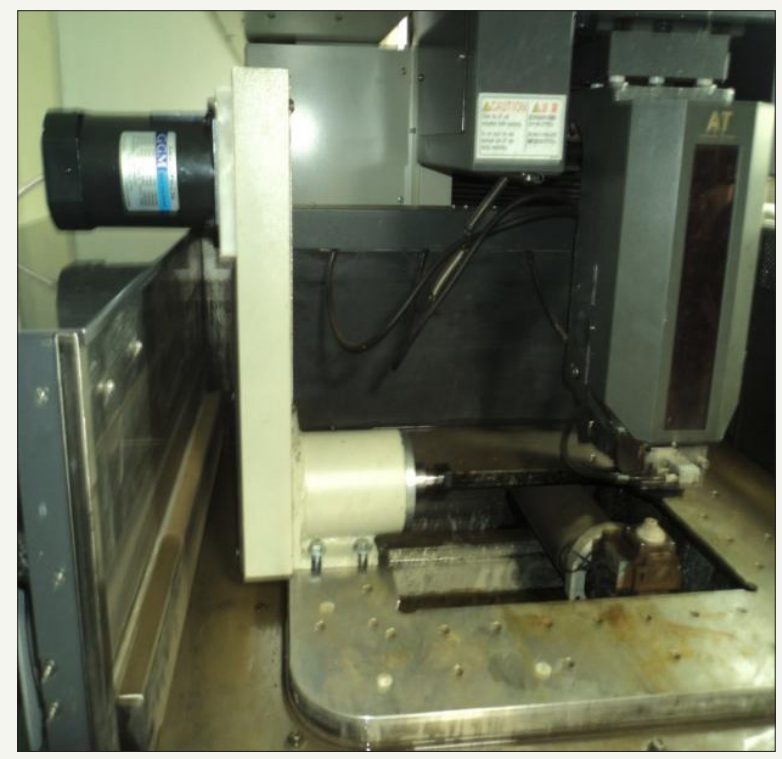

Figure 2: Experimental setup on the machine available at PSGCT.

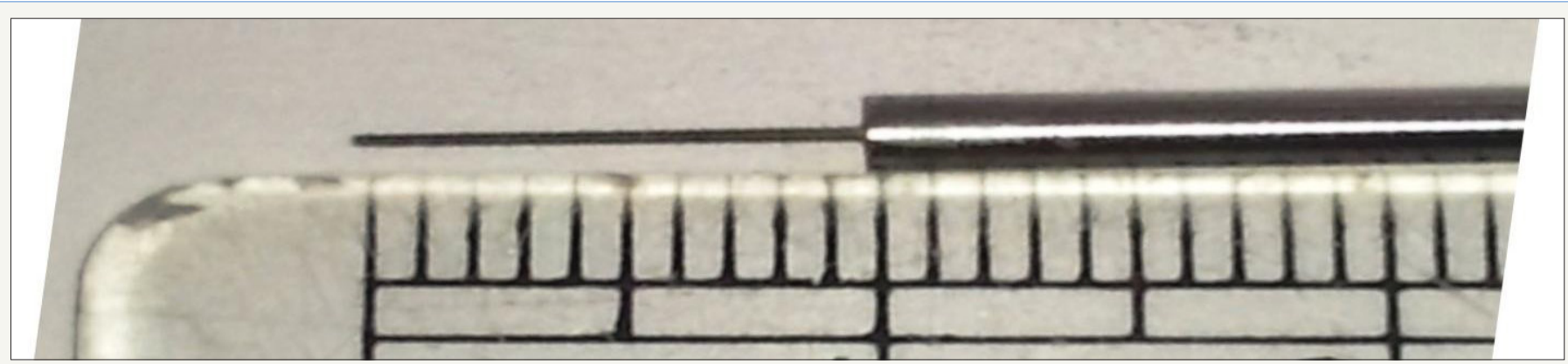

Figure 3: Specimen of $\varphi 0.40 \mathrm{~mm}$.

\section{Aim of our Project}

To produce Micro electrode on copper and brass material from wire electric discharge grinding [WEDG] with less than 40 microns of diameter and length of $20 \mathrm{~mm}(\mathrm{~L} / \mathrm{D}=20 / .4)$ with an aspect ratio of 50 and optimize the machining parameters to get good surface finish in microelectrode some of them where inspected by Scanning Electron Microscope [SEM] and performing Micro machining on hard metals like Beryllium copper in Electric Discharge Machining[EDM].

\section{Objectives}

Study of WEDG process parameters to produce components like micro electrode for micro machining on hard metals with an (L/D $=20 / 0.4$ ) aspect ratio of 50 and above, round electrodes and micro tools on hard and difficult to machine materials [Copper, Carbide and Tool steel] which subsequently can be used for micro-EDM or micro-cutting applications. To analyse the effect of process parameters (voltage, spark gap, speed and feed of wire) on MRR, Surface finish and aspect ratio of 50 with $\phi 0.4 \mathrm{~mm}$ wire by using existing CNC Wire EDM (Mitsubishi) and develop mathematical models. To manufacture of micro components like Probe, Injection nozzle and electrodes, etc.
To analyse the dimensional, form accuracy \& surface finish of the micro electrode produced and optimize the process parameters. To analyse the micro machining capability of our micro electrodes on hard metals like beryllium copper and vanadium etc... in EDM and optimize the process parameter to get better accuracy, surface finish and MRR while at micro machining. To study the effect of di-electric fluid and by adding suspensions in the fluid to investigate the quality of machining [1-6].

\section{Conclusion}

Once the process parameters were optimized then we can go for taking consultancy or job work for manufacturing of micro components and micro machining in hard metals with the help of micro electrode according to the needs of the industry. We can do further research in the same area on how the machining parameter affect the our required MRR and the surface finish while performing micro machining on hard metals in Electric Discharge Machining [EDM] and by adding emulsions or nano particles to the di-electric fluid in order to find a optimal ratio of additives for improved machining parameters and can suggest the same for the users of WEDM. 


\section{References}

1. Altshuller G (1999) The innovation algorithm: TRIZ, systematic innovation and technical creativity. Technical Innovation Center Inc, Worcester, England.

2. Chou JR (2014) An ideation method for generating new product ideas using TRIZ, concept mapping, and fuzzy linguistic evaluation techniques. Advanced Engineering Informatics 28(4): 441-454.

3. Hernandez NV, Schmidt LC, Okudan GE (2013) Systematic ideation effectiveness study of TRIZ. Journal of Mechanical Design 135: 1010091-101009-10.
4. Tan RH (2017) TRIZ, the development and dissemination in industries in China. TRIZCON 2017, 3-5 October at the Caesars Hotel and Casino in Atlantic City, NJ, USA.

5. Pahl G, Beitz W (1996) Engineering design-a systematic approach. $\left(2^{\text {nd }}\right.$ edn), Springer, London, USA.

6. Tan RH (2014) Interactive training model of TRIZ for mechanical engineers in China. Chinese Journal of mechanical Engineering 27(2): 240-248. (c) (i) Creative Commons Attribution 4.0 International License

For possible submissions Click Here

Research \& Development in Material Science
Benefits of Publishing with us
- High-level peer review and editorial services
- Freely accessible online immediately upon publication
- Authors retain the copyright to their work
- Licensing it under a Creative Commons license
- Visibility through different online platforms

